\section{Safeguard their smiles}

When faced with patients who are at high risk of developing caries, it's a good idea to give them some extra protection.

Clinpro White Varnish with TCP from 3M Oral Care is an effective shield that not only protects healthy dentition but also helps to preserve restored teeth too.

Easy to apply and with a high fluoride content that acts to defend against plaque acid in the oral cavity, Clinpro White Varnish with TCP from $3 \mathrm{M}$ is an effective barrier that can easily help high-risk patients retain a healthy smile.

For more information, call 08458734066 or visit www.3m. co.uk/Dental. 3M representatives remain contactable by phone or via video conferencing. $3 \mathrm{M}$ and Clinpro are trademarks of the $3 \mathrm{M}$ Company.

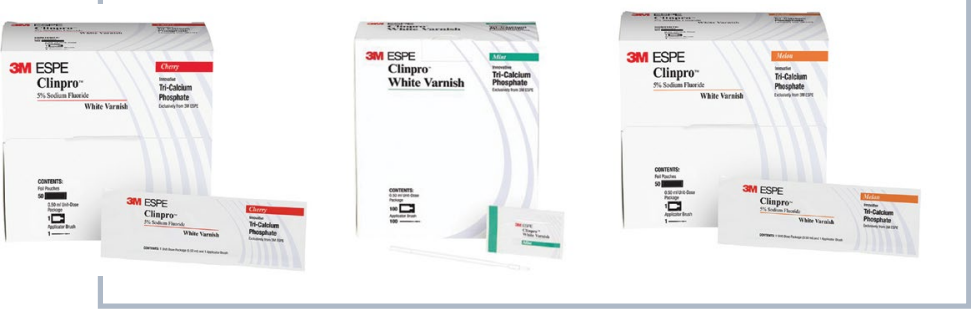

\section{Putting you in control of endodontic treatment}

VaryFlex from Endoperfection is a new and exciting range of endodontic files that offers amazing value without compromising on quality and is simple to use.

Indeed, the files have incredible flexibility due to the heat-treated nickel titanium (NiTi) alloy and a $11 \mathrm{~mm}$ shank, which is shorter than usual, making working with VaryFlex very comfortable and easy.

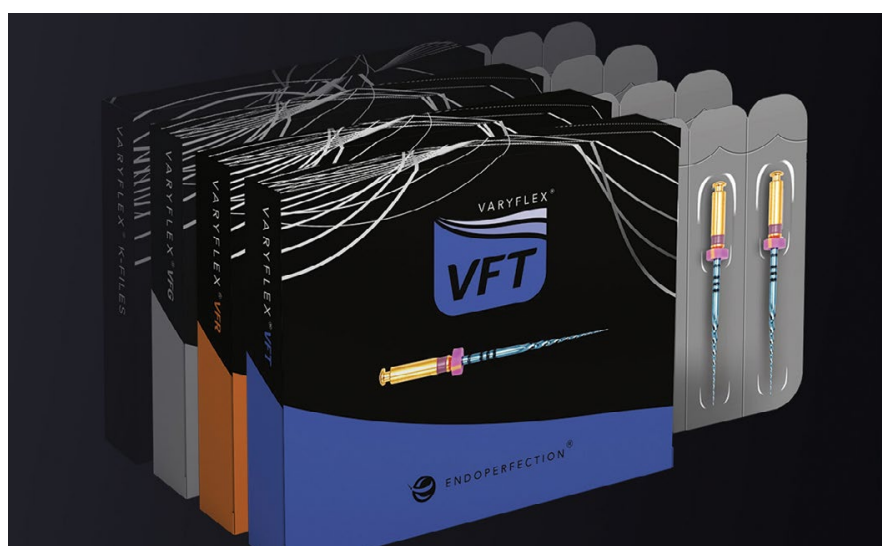

Speaking about his enthusiasm for these new files, Endoperfection founder, Charlie Nicholas, commented, 'I am passionate about all dentists gaining access to correct training and advice in relation to performing routine endodontics, as well as learning further skills to carry out more challenging cases.

'Last year saw the launch of Endoperfection, the first UK rotary file manufacturer. With our unique file systems, we now have a market leader in file design and a company ethic that can truly enthuse dentists striving to deliver unsurpassed levels of treatment for their patients.

For further information, visit endoperfection.com.

\section{Non-peroxide tooth whitening kits}

Whites Beaconsfield is the UK's leading provider of non-peroxide teeth whitening products, created by 20 -something brothers Ollie and Toby Brittan and their friend Tom Jansons at the end of 2019.

Whites Beaconsfield specialise in non-peroxide teeth whitening kits that show results after just ten minutes and range in price from $£ 9.99$ to $£ 114.99$. The products vary

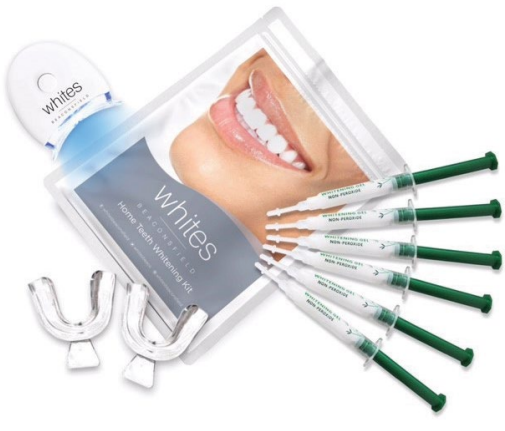
from single items to ultimate teeth whitening kits. The extensively researched natural, vegan-friendly oral care products are guaranteed to give cleaner teeth and a sparkly smile, naturally.

The non-peroxide products have been very successful so far, even during the COVID-19 pandemic, because of their low cost and convenience and because they guarantee results.

Whites Beaconsfield have also launched the Bright Smiles Foundation with 50p of every order from Whites Beaconsfield being donated to an incredible cause. The funds raised will build schools in the most deprived areas of Ghana, Guatemala and Laos.

For the full product range visit www.whitesbeaconsfield.co.uk.

\section{Care for ex-smokers}

There are many benefits to stopping smoking. Staying 'stopped' is something that patients can struggle with, and this is where the dental practitioner comes in, with the help of TANDEX high quality oral care products.

TANDEX brushes, interdental brushes and adjunctive products can give a deep, but gentle clean to mouths that may have been left more sensitive after a smoking habit.

Once a patient knows what clean really feels like, they should be less likely to want to use tobacco-based products again.

TANDEX products should be part of a long-term preventive programme to help smokers recover, alongside regular appointments.

Choose TANDEX, for a lifetime of oral health support.

For more information on TANDEX's range of products, visit tandex.dk.

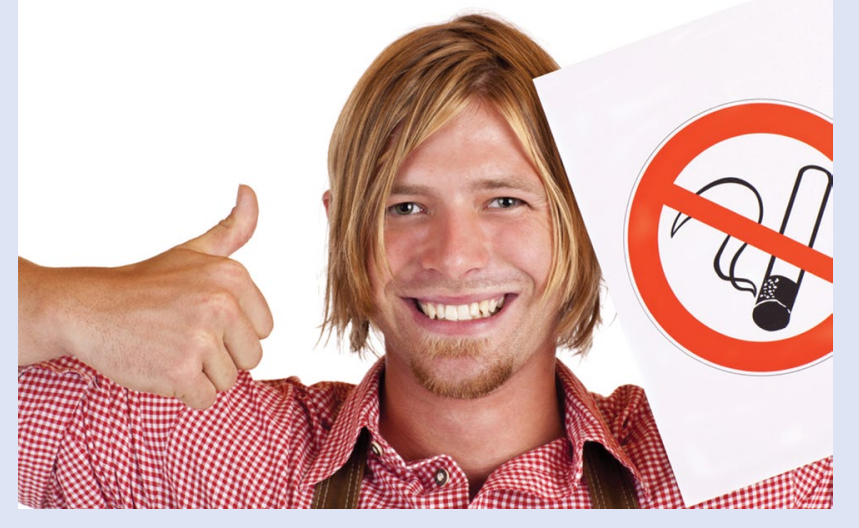

